\title{
A Evolução da Política Migratória no Mercosul entre 1991 e 2014
}

The Evolution of Migration Policy in Mercosur between 1991 and 2014

Ludmila A. Culpi ${ }^{1}$

\section{RESUMO}

O presente artigo tem como objetivo investigar o processo de construção das políticas migratórias do Mercosul, que receberam maior atenção a partir dos anos 2000, com a assinatura dos Acordos de Residência do Mercosul em 2002. A hipótese da presente pesquisa, de que a mudança na identidade do Mercosul, de um processo com ênfase econômica para a priorização da questão social, garantiu a reinvenção do bloco e a mudança de rumos da política migratória, foi confirmada. Além disso, políticas mais progressivas na Argentina condicionaram a modificação da identidade do bloco na questão da imigração.

Palavras-chave: Mercosul; política migratória; identidade coletiva.

\section{ABSTRACT}

This paper aims to investigate the process of construction of Mercosur migration policies that received more attention from the 2000s, with the signing of Mercosur residence Agreements in 2002. The hypothesis of this study, that the change in identity of Mercosur, from an economic process to a bigger prioritization of social question, guarantees the reinvention of the process and the change of direction of migration policy, was confirmed. In addition, more progressive policies of Argentina conditioned the modification of bloc's identity on the migration issue.

Keywords: Mercosur; Migration policies; colective identity.

\section{Introdução}

As políticas setorias dão forma ao processo de integração do Mercosul. A literatura de europeização ou europeanização, a qual servirá de referência para entender a formulação de políticas no âmbito do Mercosul, analisa como as decisões da União Europeia condicionam as políticas internas do dos Estados envolvidos. As políticas regionais,

${ }^{1}$ Doutoranda em Políticas Públicas, UFPR, Curitiba, Brasil. Professora de Relações Internacionais do UNINTER. Em período de Doutorado Sanduíche no Center of International Relations Studies, Universidade de Liège, Bélgica, com bolsa CAPES. 
conforme defende Modolo (2015), são fruto de uma articulação entre os diferentes níveis, envolvendo também atores não governamentais.

Solanas (2007) adota o termo "mercosulização das políticas públicas" para observar em que medida as decisões do Mercosul são incorporadas nos ordenamentos jurídicos nacionais ou condicionam os debates e as políticas nacionais dos Estados-envolvidos. Defendemos que no Mercosul ocorre uma transferência de políticas domésticas para o âmbito regional. Observa-se uma emulação das políticas de alguns Estados que se destacam em alguma questão para os Estados mais atrasados, como a Argentina que aprovou uma Nova Lei Migratória em 2003, cujo debate influenciou sobremaneira a apresentação dos Projetos do Acordo de Residência do Mercosul, o qual foi assinado em 2002, mas entrou em vigor apenas em 2009.

Assim, é relevante elaborar estudos de caso setoriais para analisar a possibilidade da difusão de política e o êxito do Mercosul na coordenação de políticas em algumas temáticas. Nesse sentido, a política migratória do Mercosul tem se modificado e tem sido fortemente influenciada por decisões tomadas domesticamente pelos Estados do bloco, com atenção especial à Argentina. 0 processo de definição do marco normativo argentino teve impacto relevante sobre a construção do mecanismo regional migratório, o que será evidenciado na presente investigação.

A pergunta que se pretende responder no presente artigo é: a alteração da identidade coletiva do Mercosul permitiu uma maior institucionalização das políticas migratórias? Tem-se como hipótese preliminar deste trabalho que existe uma modificação e uma maior institucionalização da política migratória, que foi se tornando mais progressista no bloco, o que pode ser explicado por vários fatores, incluindo a mudança identitária e a liderança da Argentina na questão.

Adota-se como referencial teórico do presente trabalho a concepção de "mercosulização das políticas públicas" e a abordagem construtivista. Com o primeiro conceito será possível compreender melhor a construção da política migratória regional no bloco, a qual é fortemente impactada por políticas nacionais. Por sua vez, o referencial construtivista permitirá analisar a outra variável de análise fundamental para compreender a evolução do tema migração no Mercosul, que é o processo de construção e modificação da 
identidade coletiva do bloco, a qual induziu a uma mudança da abordagem de temas sociais a partir de 2002 .

Em termos metodológicos, serão investigadas, além de literatura especializada na questão, as atas do Fórum Migratório de Ministros do Interior do Mercosul, o qual é responsável pela formulação da agenda migratória do bloco e as decisões e acordos do Mercosul em relação a migração desde 1991, no momento da sua criação até 2014, quando se tem acesso a mémoria institucional do bloco.

O artigo está organizado em três partes. Na primeira é analisada a contribuição da perspectiva construtivista e da concepção de "mercosulização" das políticas públicas para entender a formação da identidade do bloco e como o Mercosul impacta sobre as políticas domésticas setoriais. Na segunda parte será apresentada a política migratória nos dez primeiros anos do bloco, quando se verifica uma forte priorização dos aspectos comerciais. Na última seção será investigada a evolução da discussão e das normativas do Mercosul sobre a questão migratória a partir de 2003, com o intuito de verificar se a alteração da identidade do bloco induz a uma maior institucionalização das políticas migratórias no Mercosul.

\section{Perspectiva construstivista, identidade do Mercosul e "Mercosulização"}

Sobre identidade, Caballero (2008) sustenta que a utilização da abordagem construtivista, a partir dos conceitos de inter-relação comunicativa, com base nas "ideias" e "identidades" dos agentes é a opção mais adequada para compreender o caso mercosulino de regionalização. No presente artigo, elege-se a perspectiva construtivista dada a sua ontologia não determinística e imaterial, propondo que a base da explicação dos comportamentos internacionais é a relação social entre os agentes. Um dos pressupostos do presente trabalho é que a questão migratória é uma ideia defendida por diversos agentes no processo sul-americano, como os ministros do trabalho membros do Fórum Migratório, os quais trabalham em prol da inserção gradual da temática na agenda de debate do processo regional. 
Para o construtivismo, as ideias, identidades, interesses e comportamentos são socialmente construídos por significados e interpretações coletivas do mundo. Nas palavras de Wendt, identidade "é uma propriedade de agentes intencionais que geram disposições motivacionais e comportamentais" (WENDT, 1999, p. 224). Wendt (1999, p.338) determina que a estrutura de qualquer cultura internalizada é a sua identidade coletiva e como consequência disso uma alteração na estrutura provoca uma mudança na identidade coletiva. No caso do Mercosul, as alterações estruturais, sejam no nível doméstico dos Estados envolvidos, a partir da guinada à esquerda pela qual passaram os governos dos Estados-Parte e a criação de novos espaços de debates dentro do organismo, como o Fórum Migratório de Ministros, promoveram uma mudança na identidade coletiva do bloco. Argumentamos que o que se observou no Mercosul foi um processo de identificação entre os chefes de Estado e suas redes, os quais tinham compreensões e motivações semelhantes em relação ao processo de integração, a partir da convergência ideológica atingida.

Sobre a mudança de identidade, Caballero defende que o Mercosul experimentou um processo de reestruturação ou reinvenção. Aplicando os conceitos construtivistas, isso significa que o Mercosul passou por uma mudança de estrutura, a qual promoveu uma modificação de interesses após a crise de 1999-2002 (CABALLERO, 2013). Essa redefinição relaciona-se com a formação de uma agenda sociopolítica a partir de 2003. Certos temas emergiram no debate como os direitos das mulheres, a agricultura familiar, cooperação educacional e em saúde, migração, entre outros. Esse processo foi resultado da identificação entre os chefes de Estado do Mercosul, que possuíam uma agenda social mais progressista, a qual impactou sobre os debates e o processo de decisão dentro do bloco.

A respeito do processo de "mercosulização de políticas públicas" Solanas (2007, p.3) defende que essa concepção é inspirada na sua homóloga europeia (europeização), contudo, diferenciada pois há uma interferência maior de agentes externos, como outros organismos internacionais, na capacidade de conformação de uma política regional comum. Solanas (2007) conceitua o processo a partir da análise da experiência da transferência de políticas educacionais da Argentina para o Mercosul.

Solanas define "mercosulização" da seguinte maneira:

"mercosurización" comprendería al conjunto de procesos de ajustes institucionales, estratégicos, cognitivos y normativos que inducidos por organismos internacionales han sido incorporados en la lógica del discurso (nacional y sub-nacional) doméstica, de las estructuras políticas y de las 
políticas públicas de los principales Estados miembros del MERCOSUR, donde a partir de su consolidación interna han logrado expandir el núcleo de influencia al conjunto del bloque (SOLANAS, 2007, p. 12).

Assim sendo, analisa-se como a política migratória do Mercosul foi condicionada por políticas domésticas dos Estados-parte, especialmente da Argentina, que promoveram políticas nacionais e impactaram sobre as decisões do Mercosul. Em um segundo momento, acontece a "mercosulização", quando as políticas acordadas pelos Estados no seio do Mercosul, sob a forma de Acordos, recomendações e demais normas, são incorporadas na normativa interna dos Estados-parte ou condicionam a discussão interna sobre o tema migratório. Contudo, deve-se relativizar essa noção, pois nem todas as políticas regionais ou nacionais são frutos exclusivamente do debate inerente ao bloco sul-americano.

Para melhor compreender a política migratória e de mobilidade, buscou-se analisar a legislação da área desde a formação do bloco em 1991, com vistas a entender a evolução da tratativa na área, até 2014. Na próxima seção será investigada a formação de políticas no âmbito migratório a partir de 1991, com vistas a observar como o forte caráter comercialista imposto aos primeiros anos do processo impactou sobre as políticas de mobilidade na região.

\section{Política migratória no Mercosul de 1991 a 2001: identidade migratória com ênfase econômica}

Com relação à inserção do tema migrações na agenda do Mercosul, isso ocorreu de modo incipiente. No Tratado de Assunção não há referência ao tema da migração, apenas aparece a expressão "circulação de fatores de produção", sendo um deles as pessoas ou trabalhadores. Além disso, não existe uma Comissão do Parlamento ou um SubGrupo de Trabalho que trate o tema de modo exclusivo. 0 primeiro Subgrupo de Trabalho a discutir a questão foi o Subgrupo de Trabalho no. 11, denominado "Relações Laborais, Emprego e Seguridade Social", que funcionou entre 1991 e 1995. Esse órgão possuia uma Comissão para tratar a temática migratória (MODOLO, 2015). 0 órgão mais relevante na questão da migração é o Fórum Migratório do Mercosul, que reune os Ministros dos Trabalho dos Estados Membros. A Reunião de Ministros do Interior do Mercosul foi criada em 1997. A 
primeira reunião que tratou do tema migratório ocorreu em 30 de maio de 1997 e discutiu o intercâmbio de informação referente à legislação migratória doméstica.

Sobre o tema da ciruculação, o Conselho Mercado Comum (CMC), em 1991, definiu a instalação de portos e canais preferenciais para cidadãos e residentes dos países para região para tornar a circulação mais fácil. Em 2000 foram instalados canais privilegiados em aeroportos para dar um tratamento especial para os nacionais do Mercosul, o que representa um avanço na questão. Para viabilizar a circulação, em 1993 foi debatida a possibilidade de criação de um único documento ou passaporte Mercosul. Em 1994, foram definidas as características comuns para os passaportes com vistas a coordenar os critérios para a questão dos documentos de identidade. Esses elementos são a cor do passaporte, que é azul escuro e com a inscrição "Mercosul”. Neste ano, passou a vigorar o Documento de Viagem Provisório do Mercosul que permite o retorno ao Estado de origem (MODOLO, 2015).

Um aspecto relevante da questão da circulação no espaço regional foi a tentativa de aprimorar o sistema de indentificação de pessoas para verificação da autenticidade dos passaportes. Para supervisionar o processo foi fundado o Centro de Consulta de Documentos Pessoais do Mercosul (CCDM), criado para garantir a informação sobre indivíduos que se estabeleçam no território dos quatro Estados membros. Sobre a identificação de documentos válidos para a viagem, uma série de normas foram definidas nos anos 1990, mas nenhuma delas entrou em vigor (MODOLO, 2015).

Em 1998 foi criada a Comisão de Assuntos Migratórios dentro da Reunião de Ministros do Interior do Mercosul. No ano de 1999, foi constituído o Trânsito Vicinal Transfonteiriço que estabeleceu regras para os movimentos entre fronteiras. Foi definida a possibilidade de se fornecer autorizações para atravessar as fronteiras por até 72 horas. Desde o início do bloco os cidadãos do Mercosul não precisavam de visto para entrada como turista nos países membros. No tema do controle de fronteiras, estabeleceu-se o Acordo de Recife e o Protocolo Adicional Regulamentado, de 1993, que buscavam coordenar as atividades de controle nas fronteiras da região, bem como os recursos necessários para atingir o fim da integração nesta área. Definiu-se um modelo único de Cartão de Entrada e Saída, que harmonizou a entrada nas diferentes vias (MODOLO, 2015). 
Em 27 de janeiro de 1998 os Ministros de Brasil, Paraguai e Argentina acordaram a respeito da troca de informação sobre benefícios concedidos a estrangeiros e discutiram os controles realizados na zona da tríplice fronteira. Ainda foi discutida a implementação de um sistema de selos para estrangeiros com o visto negado, para melhorar o controle na área. Em fevereiro de 1998 o Ministro da Argentina apresentou uma proposta para a criação de uma Unidade Tripartide de Controle de Permamência, o que foi negado pelos demais países pela incapacidade de adequar isso às legislações nacionais. Nessa mesma ocasião Brasil e Argentina destacaram a necessidade de se alcançar um acordo para a implementação do cartão de Trafico Vicinal Fronteiriço, o que foi rechaçado pelo Paraguai.

Um tema que recebeu atenção no início do processo, além da questão do Registro de Estrangeiros e do Trânsito Transfonteiriço, foi o desenvolvimento de uma estratégia comum frente ao tráfico de pessoas, encabeçada pela Argentina, que propôs um Protocolo Regional sobre Tráfico de Pessoas e Migração Ilegal, o que foi acatado pelos demais membros. Esse documento se conformou na "Declaração de Assunção em matéria de Tráfico de Pessoas e Tráfico Ilícito de Imigrantes", aprovada em 8 de junho de 2001 (CULPI; PEREIRA, 2014).

Apreende-se que a evolução da temática migratória se deu de forma lenta no Mercosul, com uma preocupação nos primeiros dez anos em garantir a circulação na região com relação a temática do turismo ou o controle das fronteiras. Não havia uma preocupação em expandir e harmonizar os direitos dos imigrantes ou combater a ilegalidade. As decisões tomadas visavam atender questões conjunturais, o que demonstra que esse comportamento dos Estados refletia a identidade do bloco, que, além de se concentrar em fomentar a livre circulação para atingir o almejado mercado comum, carecia de uma interdependência maior, de um destino comum e de homogeneidade. Na sequência será estudada a legislação migratória após 2002, com o objetivo de verificar se existe um avanço maior no tema e se há uma maior preocupação com questões sociais, demonstrando que a política migratória avançou em função da alteração da identidade coletiva do bloco.

\section{Política migratória do Mercosul entre 2002 e 2014: identidade pró-social}

Em relação a questão da residência, no encontro de 22 de março de 2002 do Foro Migratório da Reunião de Ministros do Interior, a Argentina apresentou um anteprojeto de 
Acordo para o tratamento diferenciado de cidadãos do Mercosul e Associados na tramitação da regularização migratória no território de um dos Estados partes ou Associados, sem haver a necessidade de sair do mesmo. Identifica-se que esse anteprojeto foi o germe para o Acordo de Residência dos Estados parte do Mercosul, aprovado em 2002. Destaca-se o papel da Argentina, como um agente relevante, tendo em conta a sua expertise e o pensamento mais progressista a respeito da temática da imigração (CULPI; PEREIRA, 2014).

Em abril de 2004 foi realizada a primeira reunião do Foro Especializado Migratório da Reunião de Ministros do Interior do Mercosul. Uma conquista importante ocorreu no encontro de maio de 2004, a respeito de um projeto de Declaração de Princípios sobre a política migratória no Mercosul e Estados Associados, que foi assinada na reunião extraordinária de Ministros do Interior no Chile. A Declaração de Santiago sobre Princípios Migratórios, assinada em maio de 2004, é um avanço importante na coordenação da política migratória do bloco (CULPI; PEREIRA, 2014).

Na reunião de abril de 2005, a delegação paraguaia apresentou propostas para cursos de capacitação na área migratória, o que demonstra uma preocupação com a espacialização, em dois temas: funcionários de fronteira e outro em matéria de residência e admissão. No encontro de 15 a 17 de novembro de 2005, a Argentina apresentou a reativação da ideia do Programa "Pátria Grande", que consistia em um Programa de Regularização Migratória, informando que havia iniciado o programa de modo unilateral. Em 18 de novembro de 2005, os Ministros aprovaram a Declaração de Montevidéu contra o tráfico de pessoas no Mercosul e Estados Associados, assinaram a Declaração sobre o "Programa Pátria Grande” e comprometeram a facilitar a seus nacionais a documentação para a regularização (CULPI; PEREIRA, 2014).

No encontro de março de 2006 a delegação argentina sugeriu a troca de esquemas de normas migratórias entre os Estados no sentido de garantir a harmonização efetiva. Pela primeira vez houve uma preocupação com a convergência das normas internas, o que é fundamental para que se atinja o mercado comum. Outras duas questões centrais debatidas nessa ocasião foram: i) a proposta argentina de elaborar um compilado de normas e declarações do Mercosul sobre a questão migratória e ii) o projeto do "Passaporte MERCOSUL", apresentado desta vez pelo Brasil. No encontro de maio de 2006, a Argentina 
apresentou um documento demonstrando o propósito da harmonização da legislação dos Estados-Partes (CULPI; PEREIRA, 2014).

Em março de 2007 o Uruguai apresentou sua nova lei migratória, que estava sendo estudada pelo Parlamento. Ainda neste ano, foi aprovada a Lei de Refúgio do Uruguai, de 9 de dezembro de 2006. Em outubro de 2007, o Brasil propôs no Fórum Migratório a possibilidade de incluir a carteira de identidade dentre os documentos aceitos para circulação na região (MERCOSUL, 2015).

Sobre a transparência e o fornecimento de informações ao público, a Argentina propôs, na reunião de março de 2008, a elaboração de uma memória institucional do Fórum Migratório do Mercosul, para analisar o avanço das discussões na área. Em relação a expansão dos direitos, foi discutido, em 10 de junho de 2008, um acordo sobre a "Implementação da base de dados compartilhada de crianças e adolescentes em situação de Vulnerabilidade do Mercosul e dos Estados-Associados". Nesta reunião o Brasil propôs que se iniciasse uma negociação sobre o visto de estudantes, sugerindo a simplificação do tramite de solicitação. A Argentina abordou a necessidade de implementar uma troca de informações sobre o Acordo sobre tráfico de pessoas. Em novembro de 2008 foi apresentada a Declaração de Porto Alegre sobre o Acordo de Residência para nacionais do Mercosul e Estados-Associados, a qual destaca a importância da pronta entrada em vigência do Acordo de Residência, o qual é considerado a pedra angular da política migratória da região (MERCOSUL, 2015).

Em abril de 2009, foi discutido o plano de Ação Bianual sobre segurança pública com cidadania do Mercosul. Os tópicos debatidos foram o combate ao do Tráfico de Migrantes e os Mecanismos de Informações. Por iniciativa argentina, nas reuniões de 2009 foi discutida a possibilidade de se elaborar uma guia de orientação em matéria de mobilidade regional, para facilitar a aplicação dos Acordos de Residência. Em maio de 2009, o tema do tráfico de pessoas e migrantes esteve presente na pauta. Ainda neste encontro foi tratado do tema do refúgio e da participação do Mercosul neste sistema, indicando a necessidade da realização de oficinas sobre o tema. Os Ministros autorizaram alguns acordos em maio de 2009, quais sejam: "Simplificação de legislações entre os Estados-Parte do Mercosul e Estados Associados", que buscava facilitar a legislação com fins migratórios e o "Acordo para Implementação de uma base de dados compartilhada de crianças e adolescentes em 
situação de vulnerabilidade". Em agosto de 2009, foi feito um debate comparativo das infrações e sanções previstas nas Leis Migratórias de cada país, o que demonstra interesse de harmonização. Em outubro de 2009 ocorreu finalmente a ratificação dos Acordo sobre Residência para nacionais dos Estados-partes do Mercosul e Estados associados e os ministros discutiram a importância deste acordo para o avanço da política migratória no bloco (MERCOSUL, 2015).

A partir de 2010, com a expansão da circulação de pessoas na região promovida pelo Acordo de Residência, verifica-se uma preocupação maior em uniformizar a política imigratória dos Estados-Parte, através de várias iniciativas, como por exemplo a promoção de cursos sobre Proteção Internacional de Refugiados. Sobre a questão da migração, foi proposta uma matriz comparada sobre normas e procedimentos migratórios na região. Uma discussão relevante realizada em março de 2010 foi a Proposta de modificação do Acordo de Recife sobre Controles Integrados de Fronteira. A delegação da argentina propôs uma busca para atingir a simultaneidade dos controles, a partir da implementação de um mesmo local para entrada e saída de ambos os países, o que requeria um sistema compartilhado de dados. Outra discussão que demonstra a orientação para uma coordenação da política migratória é a proposta de disposições sobre proteção de refugiados, em que se busca facilitar a entrada dos refugiados. Neste encontro foi elaborado o "Acordo para a criação de Cursos de Formação em Matéria Migratória e de Proteção Internacional de Refugiados", para capacitar profissionais para lidar com as questões acima expostas (MERCOSUL, 2015).

Em novembro de 2010, foi assinada a "Declaração de Brasília sobre a entrada em vigência das normas emanadas das Reuniões de Ministros do Mercosul e Estados Associados", para assegurar a adesão das normas formuladas neste fórum por parte dos Estados-membros. Na reunião de 2011, a Argentina apresentou um projeto para elaborar um Acordo sobre normas Migratórias do Mercosul, com fins de uniformizar os procedimentos migratórios. Neste ano, foi discutido o intercâmbio de base de dados sobre pessoas que não foram localizadas e informações sobre o enfrentamento do Tráfico de Pessoas com fins de exploração laboral. O Brasil em 2011 demonstrou não desejar a construção de uma política que trate de Estados terceiros, ao defender um acordo para controle transfonteiriço que contemple apenas os estrangeiros da região. Foi discutido em 
novembro de 2011 um Projeto de Visto de Turismo comum aos países do Mercosul, o qual foi proposto pelo Brasil e relaciona- se a ideia de uma política imigratória comunitária. Ainda nesta reunião, o Brasil apresentou o projeto de Declaração sobre Gênero, Migração e Desenvolvimento, o qual indica a mudança de identidade do bloco, que se tornou mais prosocial ao associar migração a direitos humanos. A Argentina solicitou aos Ministros que retomassem a discussão sobre proteção internacional de refugiados, devido a relevância que tem tido a questão nos últimos anos (MERCOSUL, 2015).

Em março de 2012, foi discutido o Projeto de Visto de Turismo, proposto pelo Brasil, no qual os nacionais de países terceiros requentes de visto para ingressas nos países poderiam tramitar o pedido de vista apenas em um dos Estados-parte, o que revela a busca por criar uma política imigratória. Neste encontro foi negociado também um projeto para criar uma Rede de Especialistas em Segurança Documental do Mercosul, para evitar a fraude de documentos. Outro ponto tratado foi o tráfico de pessoas, referente ao qual foi proposto um guia para tratar da questão de modo conjunto. Um tema central foi a apresentação do "Programa de ações e atividades para garantir os direitos dos meninos, meninas e adolescentes migrantes e seus familiares", a partir do qual observa-se uma preocupação relevante com assegurar direitos humanos aos migrantes. Portanto, demonstra-se a maior preocupação com a questão social no trato migratório (MERCOSUL, 2015).

Um passo importante foi dado no encontro de agosto de 2012, quando na ocasião da discussão sobre refugiados e apátridas, a delegação brasileira propôs a elaboração de um Estatudo para os Refugiados do Mercosul, que é uma tentativa de uniformizar a política de recebimento de refugiados, assim como é o caso do Regulamento Dublin na União Europeia. O Brasil destacou a necessidade da adoção de uma política avançada e completa em refúgio, reassentamento e apatridia. Assim, foi acordado que haveria uma troca de experiências e informações sobre a questão. O Brasil defendeu a necessidade de se estabelecer um procedimento harmônico sobre a questão dos apátridas. Na reunião de setembro de 2012 foi discutida a necessidade de se criar um mecanismo específico de proteção de pessoas que migram em situações de emergência, por desastres naturais, climáticos e de caráter humanitário, novamente um tema de política imigratória. Durante todo o ano de 2012 foi discutido o projeto de Declaração de Princípios do Mercosul sobre Proteção de Refugiados. 
Em novembro de 2012, o Brasil informou que a nova célula de identificação estava em trâmite e incluiria o termo Mercosul. Os Ministros novamente firmaram o compromisso de implementar uma política de migração regional baseada nos Direitos humanos.

No ano de 2013, em março, foi dada continuidade a discussão sobre o projeto de Acordo Único Migratório do Mercosul apresentado pela Argentina. A Argentina propôs também a implementação de uma Rede de Intercâmbio de Informação Migratória do Mercosul, para facilitar a troca de informação entre as autoridades migratórias da região. Também se deu seguimento ao debate sobre refúgio, reassentamento e apatridia. Foi discutido o projeto sobre Acordo de Documentos de Viagem dos Estados-Partes. Neste ano, a discussão girou essencialmente em torno da questão do Acordo Migratório do Mercosul e de refugiados e apátrias (MERCOSUL, 2015).

Em setembro de 2014 foi proposto o Projeto de Memorandum de Cooperação entre a Organização Internacional de Migração e o Mercosul, com o objetivo de cooperação técnica na questão migratória. A delegação argentina apresentou um projeto de modificação da decisão que trata do visto de turistas, com o objetivo de prorrogar a permanência do turista no país de destino. Além do tema dos refugiados, outro assunto discutido foi a obrigação dos Estados em relação a proteção de crianças e adolescentes incluindo o estabelecimento de procedimentos de identificação. Um debate central foi a criação de Boas Práticas de Gestão Migratória dentro da reunião do Fórum Migratório, que seria um espaço de troca de experiências sobre avanços nacionais em relação a questão migratória, o que indica a busca pela difusão de modelos nacionais (MERCOSUL, 2015).

A partir da análise realizada, foram identificados vários temas discutidos no Foro Migratório de Ministros Mercosul entre 2002 e 2014, sendo que se destacam os seguintes: Controle e registro de estrangeiros, Acordos para livre circulação e residência, tráfico de pessoas e migrantes, proteção de refugiados, defesa de crianças e adolescentes em situação de vulnerabilidade, Acordo de residência, coordenação das políticas migratórias e trabalhistas entre os países, passaporte do Mercosul e regularização migratória. Observouse uma intensificação da discussão sobre questões ligadas a direitos humanos, como a a discussão sobre direitos dos imigrantes, refugiados, apátrias e crianças, o que comprova a modificação da identidade migratória do Mercosul a partir de 2002. 


\section{Considerações finais}

A temática da migração recebeu pouca atenção nos primeiros anos do Mercosul, quando verifica-se uma ênfase sobre o comércio. Apenas questões relacionadas a controle nas fronteiras e circulação foram debatidas, sem uma preocupação maior com aspectos sociais da migração. Por outro lado, especialmente a partir da ratificação em 2009 dos Acordos de Residência a legislação sobre circulação garantiu avanços na livre mobilidade na região. As propostas apresentadas a partir de 2002, especialmente no Fórum Migratório do Mercosul contribuiram para criação de políticas regionais sobre migração. Assim, o Mercosul é importante como fórum de troca de ideias e conhecimento, ação que molda a identidade coletiva do bloco. Observou-se a criação de mecanismos para administrar os deslocamentos e garantir a identificação e o controle nas fronteiras. Por sua vez, passaram a ser debatidos a partir de 2002 assuntos relativos aos direitos dos imigrantes, refugiados, apátrias, dentre outros. Temas mais voltados aos direitos humanos passaram a fazer parte da agenda, como os direitos das crianças e combate ao tráfico de pessoas.

Contudo, há pouco avanço no que tange a compromissos e à efetiva harmonização da legislação. Os Acordos Migratórios e de Residência, embora sejam um progresso no que tange a livre circulação de pessoas na região, são discriminatórios, não fornecendo os mesmos direitos a nacionais de Estados terceiros. Assim, há pouca vontade política de coordenar as políticas imigratórias dos Estados-Membros, ou seja, a política de imigração em relação a Estados terceiros. Além disso, embora os Estados tenham incorporado os Acordos de Residência e outras normativas a suas legislações nacionais, ainda diferem no tratamento dado a estrangeiros e nacionais do Mercosul. Ou seja, embora as normas existam, ainda há grandes obstáculos a sua implementação por parte dos Estados, o que prejudica o avanço da criação de uma política migratória regional no bloco. No nível doméstico, uma série de atores não estatais contribui para pressionar os Estados para a inclusão do tema migratório. Todavia, a formulação da política do Mercosul em si é definida sem participação efetiva da sociedade civil, o que prejudica a legitimidade das decisões.

Identificou-se em todo o processo de inserção dos temas na agenda e debates, um protagonismo da Argentina, que buscava difundir suas políticas nacionais, as quais em muitos casos foram emuladas ou copiadas pelos Estados membros, ao aprovarem Acordos 
dentro do Mercosul. A questão da reinvenção do bloco permeou o processo, pois verificouse maior priorização de temas relativos aos direitos dos imigrantes a partir de 2002, quando argumentamos ter ocorrido uma alteração da identidade do bloco, demonstrando a politização do tema migração, o qual passou a ter maior vínculo com questões sociais. Isso demonstra uma maior identificação entre os Estados em relação ao tema da migração, o qual foi orientado para uma abordagem mais social.

\section{Referências}

CABALLERO, Sergio. S. “El proceso de Integración Regional del Mercosur: ¿Qué Papel juegan los factores ideacionales? (Doctorado en Relaciones Internacionales). Universidad Autónoma de Madrid: Madrid, 2008.

CABALLERO, Sergio. Mercosur, the Role of Ideas and a More Comprehensive Regionalism. Colombia Internacional. Universidad de Los Andes, Bogotá, 78, 2013, p. 127-144.

CULPI, Ludmila A.; PEREIRA, Alexsandro E. Mercosul e políticas de migração: Análise do processo de transferência de políticas públicas migratórias pelas instituições do Mercosul (1991-2013). Anais do 38ํㅡㄹ Encontro Anual da ANPOCS, Caxambu: ANPOCS, 2014.

MERCOSUL (2015). Atas das Reuniões do Foro Especializado Migratório do Mercosul. Acesso em em: 27 de setembro de 2015. Disponível em:

http://www.migraciones.gov.ar/foro migratorio/pdf/memoria institucional n.pdf.

SOLANAS, Facundo. El impacto del impacto del MERCOSUR en la educación superior: Un análisis desde la "Mercosurización" de las políticas públicas. Archivos Analíticos de Políticas Educativa, Buenos Aires, Vol. 17, No. 20, 2009.

MODOLO, Vanina. O Mercosul Importa. A política Regional de Mobilidade Territorial. Contexto Internacional, Vol. 37, no. 2, 2015.

WENDT, Alexander. Social Theory of International Politics. Cambridge: Cambridge University Press, 1999. 